\title{
A contribuição erasmiana para a reforma da Igreja: pedagogia e catequese entre rhetorica e doctrina
}

\author{
The Erasmian Contribution to Church Reform: \\ pedagogy and catechesis between rhetorica and doctrina
}

\section{Rui Luis Rodrigues*}

Universidade Estadual de Campinas (UNICAMP), Campinas, SP, Brasil

\section{Resumo}

O objetivo deste artigo é discutir a contribuição do humanismo erasmiano para os projetos de reforma da religião cristã surgidos ao longo do século XVI. Ele parte de uma identificação dos vínculos entre pedagogia e catequese, centrais no humanismo erasmiano; a seguir, procura situar a catequese erasmiana em suas relações com a retórica (entendida enquanto instrumento não só de transmissão de conhecimentos, mas também como meio para mover a vontade dos ouvintes) e a doctrina, ou seja, a identificação de um núcleo conceitual na fé cristã que não poderia ser negligenciado. 0 quadro final que o artigo nos oferece é o de um Erasmo preocupado com a catequese e a transmissão de conteúdos doutrinários, mas também o de um humanista zeloso

RLR: Doutor em História Social, e-mail: ruiluis@unicamp.br 
pela integridade dos vínculos entre fé e vida e defensor de uma prática doutrinária que permitisse o consenso mais amplo possível entre os cristãos.

Palavras-chave: Humanismo erasmiano. Reformas religiosas do século XVI. Rhetorica. Doctrina. Minima dogmata.

\section{Abstract}

This essay aims to discuss the contribution of Erasmian humanism to the 16th-Century reform projects of Christian religion. It starts with an identification of the links between pedagogy and catechesis, central to Erasmian humanism; then, seeks to situate Erasmian catechesis in its relations with rhetoric (understood as an instrument not only for the transmission of knowledge, but also as a mean to move the will of the hearers) and doctrine, that is, the identification of a conceptual nucleus in the Christian faith that could not be neglected. Finally, the essay depicts to us Erasmus as a man concerned with catechesis and the transmission of doctrinal contents, but also as a humanist zealous for the integrity of the ties between faith and life, and defender of a doctrinal practice that would allow the widest possible consensus among Christians.

Keywords: Erasmian humanism. Sixteenth-Century religious reforms. Rhetorica. Doctrina. Minima dogmata.

\section{Introdução: Os vínculos entre pedagogia e catequese na perspectiva erasmiana}

O humanismo dito "erasmiano" representou uma das expressões mais influentes do chamado "humanismo cristão", que floresceu em especial nas primeiras décadas do século XVI. Sua origem liga-se à atividade desse prodigioso cultor dos studia humanitatis que foi Erasmo de 
Rotterdam (entre 1466 e 1469-1536): ${ }^{1}$ inequivocamente o homem mais impresso de seu tempo, cujo papel na restauração das fontes da erudição e da religião europeias foi decisivo (BATAILLON, 1983a, p. 21; MCCONICA, 1993, p. 108).

Mas a própria importância atribuída à essa figura em seu contexto histórico responde pelas não poucas polêmicas construídas em torno dela. Num certo sentido, todos quiseram se apropriar de Erasmo: Lutero pretendera atraí-lo para a defesa de suas convicções e as críticas que teceu, posteriormente, ao humanista, refletem não pouca mágoa pela recusa de Erasmo a separar-se da Igreja católica; prelados católicos, de seu lado, teriam estimado da parte do humanista uma postura mais incisiva no conflito religioso aberto na cristandade ocidental pelo protesto luterano (MANSFIELD, 1979, p. 7-114, 211). Nas gerações seguintes, as paixões em torno do legado do humanista deram margem a múltiplas apropriações: para a Ilustração setecentista, Erasmo teria sido, sobretudo, o inimigo dos monges e da superstição religiosa; o liberalismo teológico protestante (e seu congênere católico, o modernismo teológico de fins do século XIX), saudavam Erasmo como defensor de um cristianismo nãodogmático, preocupado eminentemente com questões éticas e morais (CHOMARAT, 1981, v. I, p. 13-4; MANSFIELD, 1992; FEBVRE, 2009, p. 267-88; RENAUDET, 1939 p. 122-89).

Ao longo da segunda metade do século XX, a erudição ocupada com os estudos em torno do humanismo erasmiano procurou demolir essas imagens de Erasmo que, não obstante falsas, predominavam e comprometiam a própria interpretação do legado desse humanista. O retrato que emergiu, ao fim de décadas de cuidadosas investigações, foi aquele do humanista para o qual a religião cristã não era apenas um traço cultural da sociedade a ser conservado, mas constituía a própria essência dessa sociedade; o percurso de Erasmo ex poeta theologus, portanto, não seria fruto de imposições circunstanciais, mas corresponderia ao desenvolvimento efetivo de seus interesses. Assim como sua recusa a se juntar a Lutero não podia mais ser interpretada como mera incoerência ou covardia, suas

1 Para as indicações biográficas, impossíveis nos limites deste artigo, ver HALKIN, 1987; BAINTON, 1988; HUIZINGA, 1957; TRACY, 1996 (muitas informações biográficas úteis, calcadas em bibliografia atualizada). 
ênfases aparentemente discrepantes (como suas críticas às cerimônias e às ordens religiosas, simultaneamente com sua permanência no seio do catolicismo) deveriam ser compreendidas nas complexas interrelações que possuem entre si e com a totalidade do pensamento erasmiano (RUMMEL, 1986; HOFFMANN, 1994; RODRIGUES, 2012).

A questão que se coloca para nós é a da relação que podemos enxergar entre Erasmo, e esse humanismo que, malgrado seu, construiu-se em torno de seu nome, e os movimentos de reforma que, de uma forma ou de outra, ajudaram a promover significativas transformações no panorama da cristandade ocidental a partir da terceira década do século XVI. Uma vez que se leve em consideração que os desejos de "reformar" a fé cristã não foram prerrogativas dos luteranos ou de outros grupos subsequentes, mas responderam a anseios compartilhados no interior do cristianismo ocidental desde o tardo-medievo; e desde que se examine este tema não com ambições confessionais e polêmicas, mas a partir de uma perspectiva historiográfica metodologicamente sadia, é instigante perguntar que papel desempenhou, na configuração desse cenário que sonhava com transformações importantes na vivência prática da fé cristã, esse humanista que, de resto, nos anos seguintes à sua morte, veio a ser abominado por todos os partidos envolvidos na luta religiosa, católicos e protestantes ${ }^{2}$.

Espalham-se pelas obras de Erasmo inúmeras referências que poderiam ilustrar o valor que ele atribuía à formação do indivíduo cristão, ou seja, à transmissão de conhecimentos capazes de fazê-lo dar sentido à sua fé e encaminhá-lo a uma vivência moral adequada. Nesta chave vamos encontrar o mesmo interesse pedagógico que marcou outros aspectos da atuação de Erasmo como humanista. Essa preocupação pedagógica o levou a compor diversas obras voltadas para a instrução de crianças: é o caso de De pueris statim ac liberaliter instituendis ("Sobre os meninos e a educação liberal que se deve dar logo a eles", uma declamatio escrita

\footnotetext{
2 A Erasmo não agradava a alcunha "erasmiano": "Sou cristão e reconheço a cristãos. Não tolerarei erasmistas" ("Christianus sum, et Christianos agnosco. Erasmistas non feram". Allen EE IV, p. 121, apud BATAILLON, 1983b, p. 143; todas as traduções do latim são de minha responsabilidade). Para os percalços da herança erasmiana após a morte do humanista, ver MANSFIELD, 1979; BATAILLON, 1966, p. xiv; HALKIN, 1987, p. 432-3; para uma revisão sucinta da evolução dos estudos sobre os movimentos religiosos de reforma no século XVI, ver RODRIGUES, 2012, p. 36-42; PRODI, 2006, p. 85-99.
}

Rev. Pistis Prax., Teol. Pastor., Curitiba, v. 9, n. 2, 493-522, maio/ago. 2017 
durante a viagem que Erasmo realizou à Itália, na primeira década do século XVI, mas publicada apenas em 1529), bem como de De ciuilitate morum puerilium ("Sobre a civilidade dos costumes infantis", 1530); mas a mesma preocupação encontra-se por trás de outras obras que, conquanto não dirigidas especificamente à instrução infantil, possuem um inequívoco teor pedagógico. Nos primeiros anos de sua atividade, quando ainda dependia do encargo de preceptor para sobreviver, Erasmo escreveu para o auxílio de seus alunos De copia uerborum ac rerum ("Sobre a abundância das palavras e dos assuntos"), onde explorou as diferentes possibilidades de expressão de uma mesma ideia. Os Colloquia ou Familiarium colloquiorum formulae ("Fórmulas para conversações familiares", 1522), que colaboraram enormemente para a divulgação da fama de Erasmo a partir da década de 1520, nasceram muitos anos antes, como diálogos compostos por Erasmo com o objetivo de auxiliar seus alunos no aprendizado da conversação em língua latina. Indubitavelmente, o interesse pedagógico de Erasmo baseava-se em sua concepção de natureza humana, que ecoava as noções tomistas de cooperação entre natureza e graça e da preservação, no homem, das potencialidades intelectuais após a Queda, mas que se inclinava também ao otimismo com que boa parte da Patrística grega tratava essa questão. Tal perspectiva abria largo espaço de ação para a atividade pedagógica, concebida como recurso para o encaminhamento do homem na direção dos propósitos divinos. Eis porque Erasmo pôde escrever, com simplicidade: "Coisa poderosa é a natureza, mas a educação, mais poderosa ainda, a vence" .

Essa profunda confiança na atividade pedagógica, no poder da educação, está na origem, igualmente, da preocupação erasmiana com a catequese ${ }^{4}$. Trata-se, em geral, de um vínculo bastante negligenciado,

3 "Efficax res est natura, sed hanc uincit efficatior institutio". ERASMO, De pueris statim ac liberaliter instituendis. Cito a partir da edição brasileira: ERASM0, 2006, p. 27. 0 texto latino, do qual me servi neste passo para fazer minha própria tradução, é dado em nota de rodapé. Infelizmente não tive acesso ao texto latino integral dessa obra. Para toda a questão da pedagogia erasmiana, especialmente as bases do pensamento erasmiano na síntese tomista da tradição cristã latina e na herança da Patrística grega, ver RODRIGUES, 2012, p. 315-18.

4 “Il y a une très étroite parenté entre ce qu'Erasme dit aux prédicateurs et ce qu'il conseille aux maîtres d'école: dans un cas comme dans l'autre, il s'agit de pédagogie, et cette pédagogie doit être fondée sur l'amour, non sur la peur" (CHOMARAT, 1981, v. II p. 1085). 
sobretudo pelos que pretendem ver em um Erasmo mais preocupado com a pietas, a prática piedosa, o adversário de um Lutero mais preocupado com definições doutrinárias (AGNOLIN, 2007, p. 50; em contraste, RODRIGUES, 2012, p. 318-28). Em inúmeros textos encontraremos as preocupações catequéticas de Erasmo expressas a partir da percepção que o humanista tinha da ausência, em seu tempo, de uma instrução adequada na fé. No prefácio de sua paráfrase ao Evangelho de Mateus, por exemplo, Erasmo escreveu: "Agora há muitos quinquagenários que desconhecem os votos que fizeram no batismo, que nem imaginam, de fato, o que significam os artigos da fé, a oração do Senhor, os sacramentos da Igreja" 5 .

Para remediar isso, o humanista propunha uma instrução pós-batismal mais cuidadosa e que, talvez, pudesse incluir um ato de compromisso. Posteriormente, supôs-se que a sugestão indicava menosprezo, por parte de Erasmo, dos sacramentos do batismo e da confirmação; houve quem pretendesse ver nela um apoio para o radicalismo anabatista ${ }^{6}$. O fato é que, em termos globais, a proposta feita no prefácio não dá margem para tais ilações; não se menospreza o batismo nem se coloca em discussão o crisma, com a validade do sacramento ministrado na infância permanecendo o tempo todo implícita. Para nossas finalidades no momento, o que interessa é notarmos a deficiência que Erasmo pensava observar na vivência eclesial de sua época: as pessoas frequentavam a missa, recebiam os sacramentos, mas desconheciam o que tudo isso significava.

Essa situação e suas consequências aparecem descritas com grande clareza num trecho de uma das últimas obras escritas por Erasmo, o longo tratado sobre a pregação chamado Ecclesiastae siue de ratione concionandi libri quatuor (ou Ecclesiastes siue concionator euangelicus), publicada por

5 "Nunc multi sunt quinquagenarij, qui nesciant quid uouerint in baptismo: qui ne somniarint quidem, quid sibi uelint articuli fidei, quid precatio dominica, quid Ecclesiae sacramenta" (ERASM0, 1544, p. 20). Para a proposta de fazer os batizados na infância acompanharem os sermões ("concionibus adesse") e serem, depois, examinados por homens probos ("a probis uiris") quanto àquilo que ensinou o sacerdote ("quae docuit sacerdos"), de forma que tivessem conhecimento dos compromissos feitos em seu nome no batismo ("quod susceptores illorum nomine polliciti sunt in baptismo"), ver ibidem, pp. 18-9.

6 FRIESEN, 1998. George Williams, que procura também mapear a presença de elementos do humanismo erasmiano nos ideários da "reforma radical", é mais cuidadoso. Ver WILLIAMS, 1983, p. 21-8. 
Froben em agosto de 1535 (ERASMO, 1535) ${ }^{7}$. Discutindo as funções do sacerdote, Erasmo afirma:

O ensinamento deve incluir tanto a sã doutrina quanto a admoestação, a repreensão, a consolação e a refutação dos que ladram contra a verdade evangélica. Até um leigo batiza; por sua vez o povo pode orar em lugar do sacerdote; a administração dos restantes sacramentos não é difícil. Mas cumprir a tarefa de ensinar é tanto mais difícil quanto muito mais bela, o que fica evidente por sua utilidade. O sacerdote nem sempre batiza, nem sempre unge ou absolve, mas a tarefa do ensino, sem a qual as outras são inúteis, é perpétua. Pois de que serve aos adultos terem sido batizados, se não foram ensinados pelo catequista que força tem o batismo, quais coisas importa crer, de que modo edificar o compromisso de uma vida cristã? De que serve tomar o corpo e o sangue do Senhor, se não aprenderam de que modo o sacramento foi instituído, o que realiza em nós, com que fé, com que pureza deveria ser tomado?

A preocupação de base, como fica evidente, é com a falta de compreensão das realidades envolvidas na participação dos sacramentos e de como essas realidades cooperam na edificação do "compromisso de uma vida cristã" (expressão emblemática, porque sinaliza elemento característico da perspectiva erasmiana: a importância da correspondência entre fé e vida). A função de ensinar aparece como aquilo que dá sentido, e não

7 ERASMO, Ecclesiastae siue de ratione concionandi libri quatuor. Basileae: Officina Frobeniana, 1535. Este é o título que consta do frontispício (literalmente, "Os pregadores ou quatro livros sobre o método pelo qual se deve pregar"); o título Ecclesiastes siue concionator euangelicus ("Ecclesiastes ou o pregador evangélico") aparece como cabeçalho na primeira página do texto ( $p .1$ ), logo após a carta dedicatória ( $p p . \mathrm{a}^{2}-\mathrm{a}^{3 \mathrm{v}}$ ), com 0 subtítulo "De dignitate, puritate, prudentia, caeterisque uirtutibus Ecclesiastae” (“Sobre a dignidade, pureza, prudência e outras virtudes dos Pregadores").

8 “Docendi uox complectitur \& doctrinam sanam, \& admonitionem, \& increpationem, \& consolationem, \& redargutionem oblatrantium Euangelicae ueritati. Baptizat \& laicus, orat uicissim pro sacerdote populus, non difficilis est reliquorum sacramentorum administratio: at docendi munus implere, ut longe difficillimum est, ita idem est longe pulcherrimum, quippe cuius utilitas latissime pateat. Non semper tingit, non semper ungit aut absoluit sacerdos, sed docendi munus perpetuum est, sine quo caetera sunt inutilis. Quid enim prodest adultis tinctos esse, nisi per catechistam docti fuerint, quam uim habeat baptismus, quid oporteat credere, quomodo iuxta professionem Christianam uitam instituere? Quid prodest sumptio corporis et sanguinis dominici, nisi didicerint, quomodo sacramentum hoc institutum, quid in nobis efficiat, qua fide, quaque puritate debeat sumi?" (ERASM0, 1535, p. 82). 
realidade, aos sacramentos. É preciso atentar aqui para o detalhe, caso contrário as afirmações erasmianas soarão ambíguas (e essa ambiguidade explica muito das apropriações e rejeições de seu pensamento feitas posteriormente). Erasmo maximiza a tarefa do ensino ("a tarefa de ensinar é tanto mais difícil quanto muito mais bela") e sua importância ("tarefa [...] sem a qual as outras são inúteis"). A afirmação é forte, visto que a teologia católica definia tradicionalmente a virtude do sacramento como residindo no poder de Deus que opera no próprio sacramento (ex opere operato, "pelo próprio fato de a ação ser realizada"), não dependendo de justiça por parte do fiel ou do celebrante (TOMÁS DE AQUINO, Summa Theologica, III, q. 68, a. 8, c, apud Cat. Ecl. 2000, parágrafo 1128 [p. 317-8]). Mas a sequência nos mostra que, para o humanista, a realidade do sacramento não depende da consciência despertada pela instrução: o cristão ignorante não deixa de experimentar o sacramento, apenas não sabe o que este "realiza em nós" ("quid in nobis efficiat"). O caráter inclusivo desse "in nobis" ("em nós") mostra que a realidade não é posta em dúvida pela falta de compreensão, mas fica evidente que a edificação de uma vida piedosa ("iuxta professionem Christianam uitam instituere") resta comprometida pela lacuna conceptual.

A mesma lógica - não se nega a validade dos sacramentos, mas se considera que uma vivência plena da fé deve incluir o conhecimento dos seus efeitos - transparece num trecho significativo que, à semelhança do destacado acima, integra também o Livro I do Ecclesiastae. Erasmo compara a dignidade do rei com aquela do sacerdote, concluindo que este (não somente o bispo, mas mesmo um pároco de aldeia) está revestido de uma dignidade incomparavelmente maior. Obviamente, ambos os ofícios possuem suas próprias esferas, mas o caráter eterno das atribuições do sacerdote determina sua prioridade (ERASMO, 1535, p. 68). Nessa comparação, Erasmo deixa claro que não vê os sacramentos em oposição à pregação:

O que concede a liberalidade régia? Estipêndios, bens, títulos honoríficos, tudo coisas efêmeras e expostas às zombarias da fortuna. O que concede o pregador? Através dos sacramentos da Igreja ministra a graça divina, pelo batismo faz dos filhos do inferno herdeiros do reino celeste; pela sagrada unção aduz vigor à alma contra a força do demônio; pela sagrada Eucaristia tanto une os homens entre si como os mesmos são 
levados à concórdia com Deus, e depressa são feitos um com ele; pelo sacramento da penitência dos mortos recupera vivos, dos escravos recupera libertos. Finalmente, com esforço extrai diariamente das Escrituras saudáveis manjares de doutrinas pelas quais as almas são nutridas e revigoradas, produz o vinho espiritual que verdadeiramente alegra o coração, obtém o remédio pelo qual são sanadas as verdadeiramente letais doenças da mente, produz antídotos contra a eficácia dos venenos da antiga serpente ${ }^{9}$.

$\mathrm{Na}$ ordem de exposição dos bens fornecidos pelo pregador, e que contrastam com a instabilidade dos bens proporcionados pelo rei, o primeiro lugar é ocupado pelos sacramentos. A pregação, caracterizada pelo esforço diuturno de extrair das Escrituras as doutrinas que conduzem à vida (referidas por meio de metáforas derivadas dos campos da alimentação e da medicina), aparece somente depois, introduzida por um "finalmente" (denique). A intenção me parece clara: a ênfase erasmiana no ensino não pretendia deslocar a importância concedida pela tradição aos sacramentos, mas tinha como objetivo possibilitar aos cristãos obter mais fruto da vivência eclesial através da consciência do significado dos bens espirituais que, de fato, já os enriqueciam.

Uma compreensão minimamente justa das ideias de Erasmo exige que levemos em conta, aqui, o fato de que ele escreve mormente como um retórico e, como tal, inclina sempre seus argumentos na direção do objetivo principal de seu discurso. No caso do Ecclesiastae, esse objetivo é encarecer a pregação e a contribuição fundamental que ela, enquanto lugar efetivo de catequese, pode fornecer à vivência da fé. Similarmente, em outros momentos, sua preocupação girou em torno da valorização do elemento interior da fé, que corria eventualmente o risco de ser ignorado diante da mera observância de exterioridades. Em ambos os casos ele

9 "Regia liberalitas quid donat? Stipendia, census, titulos honorificos, fluxa omnia, \& fortunae ludibria exposita. Quid Ecclesiastes? Per ecclesiae sacramenta subministrat coelestem gratiam, per baptismum ex filij gehenae facit haeredes regni coelestis; per sacram unctionem addit animo robur aduersus uim daemonum; per sacram Eucharistiam, \& homines inter sese, \& eosdem concordia conglutinans deo copulat, ut iam unum cum illo fiat; per poenitentiae sacramentum e mortuis reddit uiuos, e seruis liberos. Denique e poenu scripturarum quotidie depromit escas doctrinae salutaris, quibus saginantur \& uegetantur animae, profert uinum spirituale quod uere exhilarat cor, profert medicinam, qua sanantur morbi mentium uere letales, profert antidota aduersus uetusti serpentis uenenum efficacia" (ERASM0, 1535, p. 68). 
não pretendia opor a pregação aos sacramentos, ou a piedade interior às cerimônias. A presença do elemento retórico obriga-nos a sempre relativizar o acento enfático colocado sobre as afirmações, considerando-as dentro de seu objetivo imediato e evitando a tentação de sistematizá-las em demasia.

Conhecer a fé cristã não apenas em termos de compromisso moral, de piedade "prática", mas também em termos de um conteúdo enunciativo definido, era, portanto, um dos objetivos da pedagogia erasmiana. Tendo em vista a maneira como a respublica christiana se configurava, com profunda intersecção entre as esferas civil e religiosa, fica evidente que esse anseio erasmiano não dizia respeito apenas à religião; formar o cristão era, para ele, formar também o cidadão ${ }^{10}$. Para o humanista era o caráter profundamente cristão que habilitava para o exercício das prerrogativas cívicas, com a distinção de papéis entre príncipes e cidadãos sendo, aqui, meramente funcional (ERASMO, 1516a). Que a preocupação é pedagógica resulta claro de toda essa ênfase no ato de ensinar, ainda que um humanismo erasmiano ocupado com a transmissão de "doutrinas" talvez espante os que se habituaram a lê-lo na chave da religiosidade moralista. Mesmo a crítica que Erasmo fez à abordagem escolástica, que ele reputava inadequada por não estimular devidamente a piedade, não significou uma recusa aos conteúdos intelectuais da fé; discutiremos mais adiante tanto essas ressalvas em relação à escolástica quanto a proposta, especificamente erasmiana, de uma minima dogmata, uma suma dogmática reduzida ao mínimo essencial. Importava deixar claro, por enquanto, a presença, no humanismo erasmiano, dessa preocupação catequética, cujo caráter eminentemente pedagógico não pode ser negligenciado.

\section{A catequese erasmiana entre rhetorica e doctrina}

A catequese geralmente não é associada ao humanismo erasmiano; mas faz parte dele, na exata medida em que a instrução na fé se revela como um dos elementos mais importantes na configuração da perspectiva

10 Para o tema da respublica christiana como autocompreensão da sociedade ocidental no período medieval e durante a primeira modernidade, ver RODRIGUES, 2013; mais amplamente, RODRIGUES, 2012, p. $190-248$.

Rev. Pistis Prax., Teol. Pastor., Curitiba, v. 9, n. 2, 493-522, maio/ago. 2017 
de Erasmo. No Ecclesiastae apenas temos sistematizada, em alguma medida, uma preocupação que se encontrava espalhada pela obra erasmiana: fornecer educação cristã ao rebanho é uma das prioridades do sacerdote, entendido como catechista, como responsável pelo doutrinamento.

Para compreendermos adequadamente esse objetivo, pouco considerado, do humanismo erasmiano, precisamos levar em consideração dois elementos que lhe são constitutivos: a noção de rhetorica, instrumento indispensável, segundo Erasmo, para a realização da atividade catequética, e a maneira pela qual o humanista entendia a doctrina christiana.

O objetivo da retórica assentava-se na pretensão de mover os afetos dos seres humanos, pela via do discurso, na direção pretendida pelo orador. Sua importância na constituição da vida civil no mundo clássico é claramente perceptível: era a capacidade de se fazer ouvir que determinava, em certa medida, a participação efetiva do cidadão nos assuntos da polis; obviamente essa participação dependia também de outros aspectos, mas as habilidades retóricas desempenhavam um papel importante no conjunto. Ao mesmo tempo, as sociedades greco-latinas viam um valor extremo na palavra pronunciada, que não apenas possibilitava os discursos públicos e a vida cotidiana, mas organizava a própria vida intelectual na medida em que a leitura era, fundamentalmente, feita em voz alta (KENNEDY, 1962, p. 130-46, p. 145; KENNEDY, 1980). O aluno era previamente instruído pelo gramático, cujas preocupações giravam em torno da explicação dos autores (poetarum enarratio), do treinamento nas artes da escrita e da instrução na "arte de falar corretamente" (ars bene loquendi); a seguir era confiado ao rector, cuja preocupação básica era capacitá-lo a persuadir (ars bene dicendi, "arte do bem dizer"; cf. PEREIRA, 2000, p. 37-60, esp. p. 50-2).

Como ars específica (no sentido latino de habilidade adquirida pelo estudo e pela prática), a retórica constituía-se de três partes, que correspondiam aos diferentes objetivos do discurso: delectare (deleitar), docere (ensinar, comunicar determinados conteúdos) e mouere (mover a vontade; cf. CHOMARAT, 1981, v. II, p. 1081; MÉNAGER, 1992, p. ccxix; PEREIRA, 2000, p. 50). "Dizia bem", falava com eloquência, quem equilibrava esses elementos de forma justa. Obviamente, o próprio sentido civil do uso da retórica determinava a preeminência do mouere: esperava-se que o orador 
convencesse sua plateia e a levasse às decisões julgadas convenientes. Mas uma sociedade que atribuía tal valor ao discurso via-o também como instrumento de prazer, o que motivava a existência de relações bastante íntimas entre o mouere e o delectare. O discurso era o resultado da presença proporcional dessas três partes constitutivas.

Durante o medievo, a retórica integrou o conjunto das "sete artes liberais"; já na lista fornecida por Isidoro de Sevilha em seu Etimologias ela ocupava o segundo lugar (logo após a Gramática, definida como "ciência do falar") e dizia respeito ao "amor à elegância e à riqueza de expressão, sobretudo nas questões civis". Seu papel, no entanto, foi obscurecido no medievo tardio pela crescente importância obtida pela terceira das artes liberais, a dialética ("cognominada lógica, que separa o verdadeiro do falso por meio de sutilíssimas disputas”, no dizer de Isidoro) ${ }^{11}$. Essa tensão foi estimulada pela crescente valorização do que se poderia chamar de lógica enquanto atitude mental distinta, em oposição ao antigo paradigma analógico de pensamento; tal valorização assinalou a sociedade ocidental a partir do século XII (FRANCO JR., 2010, p. 93) e, manifesta em vários segmentos da vida cultural, ajudou a preparar o cenário para o debate entre escolásticos e retóricos que caracterizou o Renascimento.

Como se sabe, a participação de Petrarca foi fundamental para a revivescência da retórica a partir do século XIV. No humanismo petrarquiano, seu papel era sobretudo o de incendiar o coração, movendo a vontade na direção da virtude. Pesquisas recentes mostraram a necessidade de relativizar essa oposição, que já foi absoluta, entre escolásticos e humanistas, ajudando-nos a mapear os interesses e as lutas pelo poder que se esconderam, inúmeras vezes, por trás dos argumentos empregados no debate (RUMMEL, 1998; KRISTELLER, 1979; BOUWSMA, 1990). Além disso, a rejeição humanista da dialética escolástica não se deu num vácuo; a distinção possibilitada pelo tomismo entre piedade e conhecimento teológico foi primeiramente questionada pelo reflorescimento do pensamento agostiniano ao longo do século XIV (no quarto livro de seu De doctrina christiana Agostinho enfatizava a retórica como instrumento

${ }^{11}$ ISIDORO DE SEVILHA, Originum libri (“Etimologias”), I, ii, 1-3. Cito a partir de PEREIRA, 2000, p. 49. 
para o ensino da doutrina), depois pelas ênfases de místicos do século XIV como Eckhart e de teólogos do século seguinte como Jean Gerson (TRACY, 1996, p. 55-6; TILLICH, 2000, p. 205-6).

Dos aspectos da arte retórica absorvidos pelo humanismo erasmiano, dois receberam ênfase especial: a prudentia e o mouere. A prudentia determinava o conhecimento prévio do auditório, a fim de que o conteúdo do discurso fosse adequadamente adaptado. Embutia certa medida de dissimulação, visto que os mesmos conteúdos não se prestavam de forma igual a públicos diferentes; nesse sentido, Erasmo distinguia a mentira procedente do desejo de enganar (malitia) daquela oriunda da ignorância (stultitia) ou da intenção, para ele justificável, de "acomodar-se" ao auditório, ou seja, de protegê-lo falando-lhe apenas o que ele teria capacidade de ouvir (CHOMARAT, 1981, v. II, p. 1118). Comentando, nas anotações que produziu para sua edição do Novo Testamento (1516), o discurso que Paulo teria feito em Atenas (Atos 17, 22-23), Erasmo estribou-se na autoridade de Jerônimo para qualificar de "astúcia piedosa" o comportamento do apóstolo, que teria suavizado a idolatria dos gregos em seu discurso, chegando a referir-se a uma inscrição que originalmente dizia: "Aos deuses da Ásia, da Europa e da África, deuses estranhos e desconhecidos" como se dissesse apenas "ao deus desconhecido"12. De acordo com Erasmo, Paulo “de 'deuses desconhecidos' fez 'deus desconhecido' e omitiu a menção aos outros" 13 . Essa "astúcia piedosa" servia aos interesses da pregação e Erasmo a recomendou com a seguinte observação: "Pois isto era fazer-se tudo para com todos, a fim de ganhar a todos"14. De igual modo Pedro, nos sermões que abrem o livro dos Atos dos Apóstolos, teria omitido qualquer menção à divindade de Cristo para não ofender a consciência de seu auditório judaico ${ }^{15}$. A prudentia encontra-se, assim, na

\footnotetext{
12 "Titulus enim sic habebat autore, quem modo citaui Hieronymo, Dijs Asiae, et Europae, et Africae, dijs ignotis et peregrinis" ERASMO, NI: 393.

13 "Ex dijs ignotis deum fecit ignotum, et mentionem caeterorum omissit" (ERASMO, NI: 393).

14 "Hoc enim erat fieri omnia omnibus, ut omnes lucrifaceret" (ERASMO, NI: 393).

15 ERASM0, “Ep 1202 a Justus Jonas” (10/5/1521). In: CWE 8: 201-11.
} 
origem da dissimulatio ("dissimulação") erasmiana como sinal de caridade para com o auditório ${ }^{16}$.

Do ponto de vista do humanismo erasmiano, na dialética, ao contrário do que ocorria na retórica, não existia preocupação com o auditório; as demonstrações racionais sobre as quais a dialética se apoiava seriam de caráter universal e, portanto, a resistência a elas indicaria no mais das vezes uma vontade corrompida. De igual modo a dialética falharia no encargo de mover os afetos, visto que sua preocupação primordial era o convencimento racional (CHOMARAT, 1981, v. II p. 1122-3). Daí a atenção que o humanismo erasmiano dava ao mouere.

Para Chomarat, Erasmo via na dialética, dado seu caráter demasiadamente centrado na disputa, o risco potencial de uma perene alimentação de conflitos, o que se tornava ameaçador para a caridade cristã. Se os escolásticos haviam introduzido a dialética no coração da teologia, Erasmo pretendia instalar ali a retórica (CHOMARAT, 1981, v. II p. 1123-6). Mas Chomarat enxerga essa oposição em cores demasiado fortes ao afirmar que Erasmo, desejando colocar o mouere acima do docere, pretendia persuadir, mais do que demonstrar (CHOMARAT, 1981, v. II p. 1128). As observações que já transcrevi acima, retiradas do Ecclesiastae, ressaltam a preocupação com a transmissão de determinados conteúdos discursivos; para Erasmo, mover a vontade era imprescindível, mas isso só poderia ocorrer efetivamente a partir da absorção desses conteúdos. Nesse sentido é importante lembrar que a tarefa retórica dependia do equilíbrio entre as três partes constitutivas dessa arte. Erasmo rejeitava a ênfase dirigida exclusivamente ao delectare (ou seja, os discursos rebuscados, de caráter literário, mas desprovidos de força religiosa) e aquela centrada apenas no mouere (como os sermões intensamente apelativos nos quais os frades mendicantes eram especialistas), tanto quanto rejeitava a preocupação escolástica voltada

${ }^{16}$ Obviamente, a totalidade da dissimulatio erasmiana não cabe nessa definição estreita. Ela foi recurso principalmente literário cuja finalidade era proteger as bonae litterae dos ataques de seus "inimigos"; no limite, tinha também a intenção de proteger o próprio Erasmo. Sobre o tema, amplo, da dissimulatio nos inícios da época moderna, ver SNYDER, 2009; ZAGORIN, 1990; JOHNSON, 2011; BAKOS, 1991. Para a dissimulação como estratégia de sobrevivência entre os dissidentes religiosos de meados do século XVI, ver CANTIMORI, 1984a, p. 209-10; CANTIMORI, 1984b, p. 216-7; CANTIMORI, 1984c, p. 285-9; WILLIAMS, 1983, p. 9, 386-91, 643-6, 663-70. 
exclusivamente para o docere ${ }^{17}$. Para que a vontade pudesse ser corretamente movida, o conhecimento não era item dispensável.

Isto nos coloca diante do lugar ocupado, efetivamente, pela doctrina na perspectiva retórico-catequética do humanismo erasmiano. Superada a noção de que o humanista se preocupava apenas com o encorajamento na direção de uma vida moralmente correta sem dar atenção ao elemento enunciativo, precisamos sondar qual o valor específico atribuído por ele ao conhecimento doutrinário.

Já sinalizamos acima que, para Erasmo, era absurdo considerar a doutrina como algo dissociado da vida; tanto é assim que, na famosa carta escrita ao abade beneditino Paul Volz, que serviu de prefácio à edição de 1518 do grande manual erasmiano de vivência da fé cristã, o Enchiridion militis christiani ou "Manual do soldado cristão", Erasmo escrevia sobre a necessidade de ganhar o mundo para a "vida cristã" (ad Christianam uitam), evitando termos como doctrina ("doutrina") ou mesmo fides ("fé") e frisando que as disputas conceituais dos escolásticos se prestavam pouquíssimo para a vivência efetiva da piedade (ERASMO, 1563, p. $A^{5}-A^{6 v}$ ).

Contra uma herança escolástica que parecia sugerir a cisão entre doutrina e vida e considerar a fé como matéria de exclusiva concordância intelectual, o humanismo erasmiano insistia na relação indissociável entre ambas. "A primeira coisa é saber o que Cristo ensinou, a segunda é observar", de forma que "ninguém se pode considerar cristão porque discute [...] os 'instantes', as 'relações', as 'quididades', as 'formalidades', mas porque guarda e exprime o que Cristo ensinou e fez"18. O trecho, levemen-

17 Para a rejeição do rebuscamento literário de fraco conteúdo religioso, ver ERASM0, 1528, p. 384-6. Para a rejeição dos sermões apelativos, ver CHOMARAT, 1981, v. II p. 1087-8; ERASMO, 1535, p. 265 (condenam-se os exageros na descrição da paixão de Cristo e a utilização de gestos teatrais destinados a mover as emoções dos expectadores). Para o uso de expedientes apelativos nas pregações quinhentistas, ver O'MALLEY, 2004, p. 154; PROSPERI, 1995, p. 168-9, descreve prática semelhante no contexto do século XVII.

18 "Primum autem est scire quid docuerit, proximum est perstare. Neque enim ob id opinor, quisquam sibi Christianus esse uideatur, si spinosa, molestaque uerborum perplexitate, de instantibus, de relationibus, de quidditatibus ac formalitatibus disputet, sed si quod Christus docuit \& exhibuit, id teneat exprimatque" ERASMO, 1516b, fl. aaa ${ }^{6 r}$. Perstare significa literalmente "permanecer"; no contexto, tem o sentido de permanecer nos ensinos de Cristo, ou seja, de observá-los; na construção erasmiana o termo faz par com teneat (inf. tenere, "guardar"). "Quididade" traduz quidditas, termo de grande importância na filosofia escolástica; é uma substantivação do interrogativo "quid est?" (“quem [ou o quê] é?"). Ver a propósito F. MORA, 2004, v. IV p. 2433-4.

Rev. Pistis Prax., Teol. Pastor., Curitiba, v. 9, n. 2, 493-522, maio/ago. 2017 
te irônico ao fazer referência a vocábulos caros aos escolásticos, sublinha que é no nexo com a vida que a fé se evidencia. Não se trata de uma recusa ao labor escolástico, mas antes de crítica a toda tentativa de relacionar a fé à posse de determinado conhecimento teológico e não a uma atitude de abertura para a mensagem evangélica que se concretiza na prática.

Ao lado dessa característica devemos situar outra: a percepção que Erasmo tinha da natureza histórica das doutrinas cristãs. Sua aguçada sensibilidade histórica capacitava-o a perceber as modificações surgidas tanto nas expressões litúrgicas e comunitárias da fé como na elaboração doutrinal propriamente dita. Consciente dos limites da própria noção de retorno à fons fidei, a "fonte da fé", visto que boa parte dos dogmas da fé cristã foram definidos apenas nos séculos seguintes ao seu surgimento, ele percebia que a Igreja não compreendera tudo logo de início e que, portanto, estava destinada a um contínuo trabalho de aprofundamento e aclaramento doutrinal: as novas situações existentes no mundo hodierno pediriam sempre respostas novas (TRACY, 1996, p. 113-5). Nesse sentido, o "biblicismo" estrito, demonstrado por muitos reformadores protestantes no decorrer das décadas seguintes, seria estranho ao humanismo erasmiano, para o qual era natural compreender que a fé cristã, desenvolvendo-se historicamente, chegaria a compreensões e formulações não explicitamente dadas no texto bíblico. Esse trabalho seria garantido pela ação perene do Espírito Santo, que dava forma continuamente à Igreja por meio da concordância de homens eruditos e piedosos (McCONICA, 1993, p. 88). Tal postura tanto justificava, para Erasmo, as transformações dogmáticas experimentadas pela Igreja ao longo de sua história, como deixava aberta as possibilidades para novas modificações.

A relativização histórica do conteúdo doutrinário conduzia a outro elemento que, unido aos demais, dava forma efetiva à concepção erasmiana de doctrina: se a própria Igreja durante vários séculos não utilizou a palavra "transubstanciação" para descrever o mistério eucarístico, bastando-lhe reconhecer unanimemente que o corpo de Cristo encontrava-se presente no sacramento, seria preciso discernir qual era o coração da doutrina e priorizar em torno desse núcleo a concordância, ao invés de discutir seus aspectos mais exteriores, sua elaboração discursiva. Num texto de 1533 no qual questionava os abusos em torno da devoção eucarística, 
Erasmo perguntou candidamente: "Se o Cristo está totalmente presente na Eucaristia, por que não deveria ser adorado?"19 Percebe-se que a preocupação do humanista estava em não perder de vista o caráter central da doutrina - a presença de Cristo no sacramento - por causa dos detalhamentos dogmáticos que, de resto, só se processaram paulatinamente. A Igreja sobreviveu durante séculos sem definir a exata natureza da presença de Cristo no sacramento, mas não teria sobrevivido sem o próprio sacramento; esta perspectiva nos mostra como, na mente de Erasmo, a necessidade de conhecer o cerne da afirmação doutrinária, necessidade que motivou suas observações acima consideradas a propósito da oportunidade de uma percepção mais acurada do significado dos sacramentos, convivia com o reconhecimento dos limites intrínsecos às formulações humanas sobre a fé. No fundo desse reconhecimento repousava a convicção de que mente e linguagem humanas são incapazes de penetrar as profundezas do mistério divino (CHOMARAT, 1981, v. II p. 1131, com citação da Ep 1333). Nesse sentido, o humanismo erasmiano afastava-se das pretensões explicativas da teologia tomista e de seus desenvolvimentos escolásticos.

Erasmo situava-se, de fato, numa importantíssima encruzilhada em termos de transformação mental. Toda a teologia sacramental católica desenvolvera-se à sombra de um modo fundamentalmente analógico de se compreender a vida, muito mais preocupado com as semelhanças do que com a exatidão. Tomemos como exemplo o sacramento eucarístico. A Eucaristia era entendida, analogicamente, em termos metonímicos: o todo (o Cristo inteiro, corpo e sangue) encontra-se presente na parte (a hóstia), por mínima que seja (FRANCO JR., 2010, p. 97, 114-5). Operando no nível analógico, o cristianismo medieval não sentiu necessidade de definir "logicamente" o mistério eucarístico; quando o fez, finalmente, foi sob o influxo da maré que, lentamente, começava a instalar na Igreja (e na vida mental do Ocidente) o pensamento lógico. Ao enunciar em termos aristotélicos a doutrina eucarística, recorrendo às categorias de "substância" e "acidente" para explicar a transformação da hóstia em Cristo sem mudança aparente, a teologia católica vazou em moldes

19 “Si in Eucharistia totus est Christus, quur non est adorandus?" (ERASMO, 1533, p. 107). 
lógicos uma percepção religiosa fundamentalmente analógica. Obtendo estatuto doutrinal pleno por volta do século XIII, a doutrina da transubstanciação representou a tentativa de se explicar logicamente uma relação, traçada analogicamente, pela qual de há muito se afirmava a presença real de Cristo no sacramento. Ao fazê-lo em termos precisos, a doutrina expôs o flanco a críticas que lhe seriam dirigidas especialmente a partir do século XVI e que questionariam, também em termos lógicos, exatamente a possibilidade dessa presença real ${ }^{20}$.

Por sua vez, era nesse momento de ascensão da perspectiva lógica que nosso humanista se situava. Sua preocupação com a catequese foi expressa em termos de uma defesa do discurso; suas acusações, frequentes, contra determinadas devoções praticadas pelo vulgo também partiam dessa perspectiva encarecedora da enunciação de conteúdos conceituais. Todavia, Erasmo intuía os perigos representados pela atitude excessivamente lógica e percebia que a discordância em torno de determinadas formulações poderia prejudicar a recepção da própria realidade religiosa. Percebe-se nele o duplo movimento de preservação do patrimônio doutrinal da Patrística e do alto medievo, não tão claro, mas marcado por grande medida de consenso, simultaneamente ao apego a uma atitude lógica que, junto com maior clareza quanto aos conteúdos da fé, poderia conduzir a um relativo estreitamento, visto que quanto mais claro o enunciado, menores as licenças para divergir e, consequentemente, maiores as chances de dissidência. Sua postura pode ser definida como ambígua, mas trata-se de uma ambiguidade à qual ele foi obrigado pelas circunstâncias de uma religião milenar que experimentava uma complicadíssima mudança de paradigma.

O conceito erasmiano de doctrina, portanto, partia da ligação insuperável entre doutrina e vida, reconhecia o caráter histórico das formulações doutrinárias e, justamente por isto, entendia a necessidade de discernir entre o coração da doutrina (a própria realidade para a qual ela

20 LESTRINGANT, 1996. Obviamente a doutrina eucarística experimentou desenvolvimentos complexos antes da formulação da doutrina da transubstanciação; esta corresponde, de fato, ao corolário de um processo controverso cujo início remonta ao século IX. Mas o fundamental, para entendermos a perspectiva de Erasmo, é compreender que antes dessa controvérsia havia pouca preocupação em definir mais especificamente 0 mistério e que a definição dogmática, quando finalmente veio, correspondeu a uma distinta abordagem do ponto de vista mental.

Rev. Pistis Prax., Teol. Pastor., Curitiba, v. 9, n. 2, 493-522, maio/ago. 2017 
aponta) e suas formulações. Ficava implícita, assim, a possibilidade de certa flexibilização, quando se tratava de aspectos secundários. Retomando nosso exemplo para maior clareza, seria inadmissível questionar a presença de Cristo no sacramento eucarístico (aqui o cerne doutrinário), mas não a discussão da forma específica pela qual essa presença se realizava (aqui o aspecto secundário e sujeito à variação histórica). Isto nos conduz ao último aspecto a ser observado neste particular: a defesa que Erasmo fez de uma "minima dogmata".

Erasmo defendia plenamente o direito dos leigos à "conversação religiosa”, a uma mútua instrução e edificação em assuntos de doutrina (ERASMO, 1516b, fl. aaa ${ }^{4 \mathrm{v}}$ - aaa ${ }^{5 \mathrm{r}}$; ERASMO, 1522, p. 242). Por que tais temas seriam vedados a eles e confiados apenas aos teólogos, uma vez que todos foram selados pelo mesmo batismo? Essa ênfase evidenciava uma instância onde a doctrina encontrava plenamente seu lugar junto ao povo "comum": edificar-se mutuamente na fé mediante o aprofundamento na doutrina cristã seria um direito de todos os que professam a fé em Jesus. Mas para Erasmo o trabalho de "definir" a doutrina não é função leiga, uma vez que pressupõe uma série de competências específicas (ERASMO, 1522, p. 242). O humanismo erasmiano não se opunha à tarefa de definição dogmática, realizada por pessoas habilitadas para tanto, pela razão muito simples de que sem esse trabalho não existiria conteúdo a respeito do qual crer. Mas como deveria se processar, no entender de Erasmo, essa tarefa?

Já respondemos em parte a essa pergunta. Havia que considerar a distância entre o coração da doutrina e as possibilidades históricas de sua formulação. Era preciso cuidado para que a excessiva atenção ao trabalho definidor não se tornasse obstáculo para o real significado da doutrina: a edificação da vida cristã. A maneira de evitar esse risco era dupla. De um lado, o teólogo deveria, ele mesmo, ser movido pela piedade. Se a junção entre doutrina e vida não se processa nele mesmo, como poderia se processar nos que recebiam os frutos de seu trabalho teológico? Não se podia pretender do teólogo, como atitude básica, menos do que se esperava do próprio leigo que Erasmo desejava estimular à conversação piedosa: "Essa pérola incomparável não considera digno 
nem um amor vulgar, nem um amar dividido; ela requer ânimo sedento, não menos do que isso"21.

Em segundo lugar, era preciso discutir a própria natureza do vocábulo "dogmata" ou conjunto de doutrinas. Num texto publicado por Erasmo em 1526 como resposta a um panfleto editado por Leo Jud (c. 1482-1542), colaborador de Zwínglio, que atribuía ao humanista, em conjunto com Lutero, determinadas opiniões sobre a Eucaristia, Erasmo abordou de forma clara sua concepção de dogmata ${ }^{22}$. Após assinalar que suas convicções sobre a doutrina eucarística estavam em conformidade com o entendimento tradicional da Igreja e explicar detalhadamente os locais onde, em suas obras, abordou essa doutrina, ${ }^{23}$ Erasmo afirmou que os dogmata incluíam três gêneros distintos:

Há três gêneros de doutrinas. Primeiro há aquelas que sem controvérsia e com amplo consenso a Igreja católica mantém, como as que estão expressamente contidas nas Sagradas Escrituras e no símbolo dos apóstolos, às quais eu consentiria ajuntar as que são decretadas em Concílios regularmente convocados e concluídos. O segundo gênero é daquelas sobre as quais a autoridade da Igreja não se pronunciou de maneira conclusiva e sobre as quais os teólogos ainda não decidiram. O terceiro gênero é daquelas que nos são impostas como oráculos da Igreja quando são opiniões de homens, que frequentemente conduzem às rixas e dissensões e pouco ou nada à piedade ${ }^{24}$.

21 "Non dignat hoc incomparabile margaritum, uel uulgariter amari, uel cum alijs diligi. Sitientem requirit animum, \& nihil aliud sitientem" (ERASM0, 1516c, fl. bbb1v). A "pérola incomparável", de acordo com 0 contexto, é o conhecimento da "filosofia celeste" (philosophiam coelestem).

22 ERASMO, 1526. Trata-se da Detectio praestigiarum cuiusdam libelli germanice scripti, ficto autoris titulo, tum hac inscriptione, Erasmi \& Lutheri opiniones de Coena domini. Basileae: Froben, 1526 ("Identificação dos enganos de certo panfleto escrito em alemão com falso título de autoria e esta inscrição, Opiniões de Erasmo e de Lutero sobre a Ceia do Senhor"). Sobre Leo Jud, ver BIETENHOLZ, 2005, p. 248-9.

${ }^{23}$ Para alguns exemplos, ver ERASMO, 1526, p. $\mathrm{C}^{2}, \mathrm{C}^{4}-\mathrm{C}^{4 v}, \mathrm{C}^{5}, \mathrm{C}^{5 \mathrm{v}}, \mathrm{C}^{5 i i}$.

24 "Dogmatum triplex est genus. Primum est eorum quae citra controuersiam magnoque consensu tenet ecclesia catholica, qualia sunt quae expresse continentur in sacris literis, \& in symbolo apostolorum, quibus adiungi patiar quae in concilijs rite conuocatis ac peractis decreta sunt. Secundum est eorum de quibus nondum euidenter pronunciauit autoritas ecclesiae, \& de quibus inter sese etiamnum disceptant Theologi. Tertium est eorum quae nobis ut ecclesiae oracula obtruduntur, quum sint opiniones hominum, frequenter

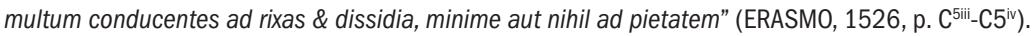

Rev. Pistis Prax., Teol. Pastor., Curitiba, v. 9, n. 2, 493-522, maio/ago. 2017 
Dessa declaração podemos depreender que, para Erasmo, dogma deveria ser apenas e tão somente uma doutrina que se enquadrasse no primeiro sentido. Nesse campo abria-se espaço para o desenvolvimento doutrinário, desde que arbitrado pelo consenso da Igreja, o magnus consensus ao qual o humanista se referiu, cujo lugar apropriado de expressão era o concílio ecumênico. Os outros dois sentidos apresentam as demais instâncias onde se processava o desenvolvimento doutrinário: o trabalho teológico, feito no interior da Igreja, devia alcançar ele próprio certo consenso e, enquanto isso não acontecia, a formulação doutrinária podia ser feita, mas não deveria pretender um caráter vinculante. Em outras palavras, é quando a segunda instância, a do trabalho teológico, se torna consensual, que se prepara o caminho para a definição dogmática por excelência no âmbito conciliar. Finalmente, havia um campo restante de atuação, cuja legitimidade Erasmo não condenava: o das opiniões humanas (opiniones hominum). O problema com essa terceira instância encontrava-se na tentativa por parte de alguns de transmitir essas opiniões como se representassem o magnus consensus Ecclesiae, o amplo consentimento da Igreja. Em suma, quando se pretendia fazer passar opiniões humanas (legítimas apenas enquanto tais) por decisões eclesiásticas que, por sua natureza, obrigavam todos os cristãos à obediência.

Nesse sentido, Erasmo entendia que era necessário circunscrever o trabalho de definição dogmática. Nem todas as doutrinas da fé deveriam ser dogmas e a tentativa de elevar "opiniões" a essa categoria suprema oferecia o risco de multiplicar indevidamente os hereges, visto que "quanto mais dogmas, mais matéria há para heresia" (Ep 1451 a Warham", 5/1/1523, in CHOMARAT, 1981, v. II p. 1131). A percepção desse risco - que, obviamente, tornou-se mais clara à medida que as controvérsias religiosas se multiplicaram durante a década de 1520 - já motivava, em 1518, a famosa proposta que Erasmo consignou na carta ao abade beneditino Paul Volz:

O mais cômodo seria, no meu entender, que se confiasse a alguns homens ao mesmo tempo pios e doutos a tarefa de compendiar, a partir das fontes puríssimas dos Evangelistas e dos Apóstolos, a partir dos mais aprovados intérpretes, todo o conjunto da filosofia do Cristo, da forma mais simples, 
porém erudita; da forma mais breve, porém clara. O que pertence à fé, que seja tratado no menor número possível de artigos. O que pertence à vida, seja tratado também em poucas palavras, de tal forma que se compreenda ser o jugo de Cristo manso e suave, não rude $[\ldots]^{25}$.

A distinção entre fé e vida refere-se de um lado às doutrinas em que se deve crer e, de outro, ao comportamento que essa fé deve refletir na vida. Em ambos os casos, o humanista visava a simplicidade: sem prejuízo para as investigações que os doutos pudessem fazer, o coração da fé cristã seria preservado nessas doutrinas indispensáveis e nessas práticas sem as quais o cristianismo restaria descaracterizado. Erasmo não pretendia limitar a totalidade da expressão da fé cristã a essa minima dogmata, esse conjunto mínimo de dogmas e de práticas; o que ele pretendia era a identificação do núcleo essencial da fé com esse mínimo, de forma que a diversidade, possível numa série de questões, opiniões e comportamentos, não representasse a exclusão da comunhão cristã.

Com este programa em mente, Erasmo escreveu a Jean Carondelet, na carta que prefacia a edição das obras de Santo Hilário feita pelo humanista:

A suma de nossa religião é paz e concórdia, que não se pode manter a menos que se observe uma condição: definir o menor número possível de dogmas e para muitas outras coisas deixar a cada um seu próprio julgamento. De fato, muitas coisas são por demais obscuras. [...] Para muitas questões agora apela-se ao concílio ecumênico; faria-se melhor em enviá -las ao dia onde, tendo desaparecido o enigma e o espelho, veremos a Deus face a face ${ }^{26}$.

25 "Commodissimum itaque mea sententia fuerit, si muneris hoc uiris aliquot iuxta pijs ac doctis delegetur, ut ex purissimis fontibus Euangelistarum \& Apostolorum, ex probatissimis interpretibus uniuersam Christi philosophiam in compendium contrahant, ita simpliciter, ut tamen erudite; ita breuiter, ut tamen dilucide. Quae pertinent ad fidem, quam paucissimis articulis absoluantur. Quae ad uitam, item paucis tradantur, \& sic tradantur, ut intelligant Christi iugum blandum \& commodum esse, non asperum [...]" (ERASM0, 1563, p. $\left.A^{7 \mathrm{v}}-A^{7 \mathrm{~T}}\right)$.

${ }^{26}$ ERASMO, Ep 1334 a Jean Carondelet (5/1/1523). Cito a partir de LECLER, 1994, p. 144. A expressão “enigma e o espelho" é uma referência a 1 Coríntios 13, 12 (“uidemus nunc per speculum in aenigmate”, VL). 
Talvez a principal razão do fracasso desse projeto esteja no fato de que a minima dogmata minimizava demais a dimensão lógica. A necessidade de especificação confessional se colocava como exigência da própria configuração adquirida por aquele momento histórico e pelas ferramentas novas que as diferentes dissidências religiosas apresentavam. Num momento em que, pela intensificação do debate, a necessidade de clareza parecia se colocar com grande energia, e no qual uma mentalidade cada vez mais lógica parecia oferecer excelentes possibilidades de expressão discursiva, falar em minima dogmata, em deixar o máximo possível ao arbítrio do julgamento de cada um, em esperar a eternidade "sem espelho e enigma" para alcançar esclarecimento, talvez fosse pretender demasiado. Erasmo apresentava, para as difíceis circunstâncias de sua época, uma solução bonita, mas desprovida de exequibilidade. Acrescente-se a isso o fato de que diversos outros fatores também inviabilizaram essa proposta erasmiana; entre eles, e de não pouca importância, o próprio horizonte político, no qual as disputas confessionais claramente se imiscuíram ${ }^{27}$.

Nascida de sua profunda inquietação pedagógica, a preocupação erasmiana com a catequese se constituiu num dos mais importantes traços desse humanismo; quiçá, na sua contribuição mais efetiva para os sonhos de reforma da Igreja que eram tão numerosos nas primeiras décadas do século XVI. Os limites deste artigo não nos permitem explorar mais detidamente os instrumentos que Erasmo parece ter identificado como ideais para essa atividade catequética: a leitura bíblica pelo fiel, seja do texto latino por alguém instruído nessa língua, seja de traduções vernáculas, às quais o humanista nunca se opôs (ainda que Erasmo considerasse fundamental a mediação hermenêutica da Igreja) ${ }^{28}$; a liturgia, que na bela sobriedade de seu conjunto deveria também oferecer ricas possibilidades

27 Resultaria anacrônico tanto imaginar a possibilidade de que questões religiosas e políticas fossem, naquele contexto, resolvidas em separado, quanto pretender que os poderes políticos tenham se valido das questões religiosas, instrumentalizando-as. Para as relações complexas entre religião e política nesse período, ver RODRIGUES, 2012, p. 149-309 (capítulo 3, “Concepções políticas, entre humanismo cívico e humanismo erasmiano") e p. 370-452 (capítulo 5, "Uma tentativa de compreensão dos processos de confessionalização").

${ }^{28}$ ERASMO, 1516b, fl. aaa ${ }^{4 v}$. Ver RODRIGUES, 2012, p. 80-3, 118-9. Para o reconhecimento, por Erasmo, do caráter complexo do texto bíblico e da necessidade de "mediação hermenêutica", ver ERASMO, 1563, p. $A^{7 v}$; RODRIGUES, 2012, p. 98-100, 345. 
de instrução; ${ }^{29}$ e a pregação, que Erasmo, como vimos, encarecia enormemente, e à qual dedicou sua última grande obra ${ }^{30}$.

O fato de não ter se revelado viável a implantação desse "projeto" erasmiano de reforma nada diz quanto ao seu valor implícito. Aliás, isto pouco nos interessa enquanto historiadores, preocupados que estamos em compreender o fenômeno histórico que foi o humanismo erasmiano, e não em defendê-lo ou vindicá-lo. Mas não nos escapa que, se por um lado a própria valorização da lógica, no contexto do século XVI, colaborou para inviabilizar o sonho de uma minima dogmata e seus benefícios para as relações entre os cristãos, por outro lado não é de estranhar que uma época que submete à crítica a própria noção moderna de lógica, como é o caso do pensamento ocidental a partir da segunda metade do século $\mathrm{XX}$, encontre novas inspirações nesse ideal erasmiano. Quando a Igreja Católica Romana realizou, no Concílio Vaticano II (1962-1965), sua grande obra de reforma e de aggiornamento, que pode ser emblematicamente representada pela atenção cada vez maior à catequese e ao acompanhamento pastoral do rebanho, pela ênfase no acesso dos leigos à Escritura em traduções modernas e pela instituição de liturgias em vernáculo, é óbvio que superou, em várias direções, as expectativas nutridas pelo humanismo erasmiano; o interesse do Concílio, de resto, era responder a uma época que em nada se assemelhava àquela das primeiras décadas do século $\mathrm{XVI}^{31}$. Mas é inegável que, nesse complexo processo, deram-se, nessa

${ }^{29}$ ERASMO, 1533, p. 27-8, 103. 0 caráter mistagógico da liturgia é lapidarmente definido por Erasmo em outra obra, o Modus orandi Deum, de 1525: In hoc enim sunt utiles ceremoniae, ut per uisibilia ad inuisibilia proficiamus ("Pois as cerimônias são úteis para nos fazer avançar através das coisas visíveis para as coisas invisíveis") ERASMO, 1525, p. $\mathrm{f}^{4 \mathrm{v}}$.

${ }^{30}$ Si qui docet ardet, facile accendet, si uehementer gaudet iis quae docet, facile transfundet eundem affectum in animos auditorum ("Se quem ensina arde, facilmente inflama; se encontra regozijo naquilo que ensina, facilmente transfere os mesmos afetos aos espíritos dos que o ouvem"), escreveu Erasmo sobre seu ideal de pregador na carta através da qual dedicou ao rei D. João III, de Portugal, sua edição dos sermões de João Crisóstomo (ERASMO, 1527, fl. $a^{4}$ ). Para considerações mais detalhadas sobre 0 ideal de pregação de Erasmo, incluindo uma análise do Ecclesiastae siue de ratione concionandi, ver RODRIGUES, 2012, p. 350-61.

${ }^{31}$ De forma sintética, ver COMP. VAT. II 1986; com sínteses importantes e análises atualizadas, ver ALMEIDA, et al. 2013; PASSOS e SANCHEZ, 2015. Para o Vaticano II como "concílio erasmiano", ver HALKIN, 1987, p. 425-35, esp. p. 433-4 (com bibliografia). Para a crítica do paradigma lógico de pensamento desde meados do século XX, ver FRANCO JR., 2010, p. 93-4, esp. p. 94 nota 4.

Rev. Pistis Prax., Teol. Pastor., Curitiba, v. 9, n. 2, 493-522, maio/ago. 2017 
Igreja da qual, em seu tempo, Erasmo se considerava parte, mudanças e transformações que não seriam estranhas aos ideais desse humanismo.

\section{Abreviações}

Allen EE

ASD

Cat.Ecl. 2000

Comp. Vat. II 1986

CWE

Ep

NI

$V L$
P. S. Allen (ed.), Opus epistolarum Desiderii Erasmi Roterodami denuo recongnitum et auctum per P. S. Allen. Oxford: Oxford University Press, 12 vols., 1906-1965

Opera omnia Desiderii Erasmi Roterodami recognita et adnotatione critica instructa notisque illustrata. Amsterdam/Oxford: North Holland Publishing Company, 1969 -, vários volumes Catecismo da Igreja Católica. Edição Típica Vaticana. Tradução. São Paulo: Loyola, 2000 (Libreria Editrice Vaticana, 1997)

Compêndio do Vaticano II. Petrópolis: Vozes, $18^{\mathrm{a}}$. edição, 1986

Collected Works of Erasmus. Toronto: University of Toronto Press, 1975 - (vários volumes). Epístola

Erasmus von Rotterdam. Nouum Instrumentum. Basel: 1516. FaksimileNeudruck mit einer historischen, textkritischen und bibliographischen Einleitung von Heinz Holeczek. Stuttgart: Friedrich Frommann Verlag - Günther Holzboog GmbH \& Co., 1986

Vulgata Latina. Madrid: BAC, 1991

\section{Referências}

\section{Fontes erasmianas}

ERASMO 1516a ERASMO, Institutio principis christiani. In CWE 27: 203-88 
Erasmo 1516b Erasmo, "Paraclesis ad Lectorem Pium" ("Exortação ao Piedoso Leitor"). NI: fl. $\mathrm{aaa}^{3 v}-\mathrm{bbb}^{1}$

ERASMO 1516c ERASMO, "Erasmi Roterodami Methodus" ("Método de Erasmo Roterodamo"). NI: $\mathrm{bbb}^{1}-\mathrm{bbb}^{5 \mathrm{v}}$

ERASMO 1521 ERASMO, "Ep 1202 a Justus Jonas” (10/5/1521). In CWE 8: 201-11

ERASMO 1522 ERASMO, "Conuiuium religiosum” ("O Banquete Religioso"). In ASD I, 3: 231-66

Erasmo 1525 Erasmo, Modus orandi Deum. Basileae: Apud Ioannem Frobenium, 1525

ERASMO 1526 ERASMO. Detectio praestigiarum cuiusdam libelli germanice scripti, ficto autoris titulo, tum hac inscriptione, Erasmi \& Lutheri opiniones de Coena domini. Basileae: Froben, 1526

ERASMo 1527 ERASMO, "Serenissimo Lusitaniae Regi Ioanni, Huius Nominis Tertio, Emanuelis filio". In IDEM, Diui Ioannis Chrysostomi Archiepiscopi Constantinopolitani \& diui Athanasii Alexandrini Archiepiscopi lucubrationes aliquot non minus elegantes quam utiles, nunc primum uersae \& in lucem aeditae per Des. Erasmum Roterodamum. Basileae: Apud Ioan. Frobenium, 1527, fls a-a5

ERASMo 1528 ERASmo, "Ciceronianus siue De optimo dicendi genere”. In CWE 28: 342-448

ERASMO 1533 ERASMO, De sarcienda Ecclesiae concordia. Basileae: Ex Officina Frobeniana, 1533

ERASMO 1535 ERASMO, Ecclesiastae siue de ratione concionandi libri quatuor. Basileae: Officina Frobeniana, 1535

ERASMo 1544 ERASMO, "Des. Erasmus Roterodamus Pio Lectori" ("Epístola ao Piedoso Leitor", 1522), in IDEM. In evangelium Matthaei paraphrasis. Leiden: Seb. Gryphium, 1544

ERASMO 1563 ERASMO, "Epistola ad Paulum Volsium" (1518), in IDEM, Enchiridion Militis Christiani. Coloniae: Apud Haeredes Arnoldi Birckmanni, 1563, pp. $\mathrm{A}^{2}-\mathrm{C}^{1}$ 
ERASMo 2006 ERASmo, De pueris. Tradução. São Paulo: Editora Escala, 2006

\section{Estudos citados}

AGNOLIN, A. Jesuitas e selvagens: A negociação da fé no encontro catequético-ritual americano-tupi (séc. XVI-XVII). São Paulo: Humanitas Editorial, 2007.

ALMEIDA, J. C.; MANZINI, R.; MAÇANEIRO, M. (orgs.). As Janelas do Vaticano II. A Igreja em Diálogo com o Mundo. Aparecida/SP: Santuário, 2013.

BAINTON, R. Erasmo da Cristandade. Trad. Lisboa: Fundação Calouste Gulbenkian, 1988.

BAKOS, A. E. “'Qui nescit dissimulare, nescit regnare': Louis XI and Raison d'État during the Reign of Louis XIII". Journal of the History of Ideas, v. 52, p. 399-416, 1991.

BATAILLON, M. Erasmo y España. Estudios sobre la historia espiritual del siglo XVI. México: Fondo de Cultura Económica, 2a ${ }^{\mathrm{a}}$. ed. corrigida e aumentada, 1966. (reimpressão 1996).

BATAILLON, M. "Actualidad de Erasmo". 2a . ed. In: BATAILLON, M. Erasmo y el erasmismo. Barcelona: Editorial Crítica, 1983a. p. 15-30.

BATAILLON, M. "Hacia uma definición del Erasmismo". 2a . ed. In: BATAILLON, M. Erasmo y el erasmismo. Barcelona: Editorial Crítica, 1983b. p. 141-61.

BIETENHOLZ, P. G.; DEUTSCHER, T. B. Contemporaries of Erasmus: A Biographical Register of the Renaissance and Reformation. Supplement to Collected Works of Erasmus. Toronto: University of Toronto Press, 2005. (3 vols. em 1).

BOUWSMA, W. J. A Usable Past: Essays in European Cultural History. Berkeley/Los Angeles: University of California Press, 1990.

CANTIMORI, D. "El círculo de Juan de Valdés y los demás grupos evangélicos". In: CANTIMORI, D. Humanismo y religiones en el Renacimiento. Barcelona: Ediciones Península, 1984a. p. 203-12. 
RODRIGUES, R. L.

CANTIMORI, D. "Los hereges del movimiento italiano de Reforma". In: CANTIMORI, D. Humanismo y religiones en el Renacimiento. Barcelona: Ediciones Península, 1984b. p. 213-23.

CANTIMORI, D. "Humanismo y religiones en el Renacimiento". In Idem, Humanismo y religiones en el Renacimiento. Tradução. Barcelona: Ediciones Península, 1984c. p. 269-305.

CHOMARAT, J. Grammaire et Rhetorique chez Érasme. Paris: Société d'Édition Les Belles Lettres, v. 2, 1981.

FEBVRE, L. O problema da incredulidade no século XVI: A religião de Rabelais. São Paulo: Companhia das Letras, 2009.

FERRATER MORA, J. Dicionário de Filosofia. São Paulo: Loyola, 2a . edição, v. 4, 2004.

FRANCO JR. H. “Modelo e imagem: o pensamento analógico medieval". In: FRANCO JR. H. Os três dedos de Adão. Ensaios de Mitologia Medieval. São Paulo: Edusp, 2010. p. 93-128.

FRIESEN, A. Erasmus, the Anabaptists, and the Great Commission. Grand Rapids/ Cambridge, Eerdemans, 1998.

HALKIN, L. E. Erasme parmi nous. Paris: Fayard, 1987.

HOFFMANN, M. Rhetoric and Theology: The Hermeneutics of Erasmus. Toronto: University of Toronto Press, 1994.

HUIZINGA, J. Erasmus and the Age of Reformation. New York: Harper Torchbooks, 1957. (original holandês de 1924).

JOHNSON, J. H. Venice incognito: masks in the serene republic. Berkeley and Los Angeles: University of California Press, 2011.

KENNEDY, G. A. “An estimate of Quitilian”. American Journal of Philology, n. 83 p. 130-146, 1962.

KENNEDY, G. A. Classical Rhetoric and its Christian and Secular Tradition from Ancient to Modern Times. Chapel Hill: University of Carolina Press, 1980. 
KRISTELLER, P. O. Renaissance Thought and its Origins. New York: Columbia University Press, 1979.

LECLER, J. Histoire de la tolérance au siècle de la Réforme. Paris: Albin Michel, 1994.

LESTRINGANT, F. Une sainte horreur - ou le voyage en Eucharistie: $x v i^{\mathrm{e}}-x v i i{ }^{\mathrm{e}}$ siècle. Paris: Presses Universitaires de France, 1996.

MANSFIELD, B. Phoenix of His Age. Interpretations of Erasmus, ca. 1550-1750. Toronto: University of Toronto Press, 1979.

MANSFIELD, B. Man on his own: Interpretations of Erasmus, c. 1750-1920. Toronto: University of Toronto Press, 1992.

MCCONICA, J. “Erasmus”. In: THOMAS, K. (ed.), Renaissance Thinkers. Oxford/ New York: Oxford University Press, 1993. p. 5-112.

MÉNAGER, D. "Rhétorique". In: BLUM, C.; GODIN, A.; MARGOLIN, J-C.; MÉNAGER, D. (ed.). Érasme: Éloge de la folie, Adages, Colloques, Réflexions sur l'Art, l'Éducation, la Religion, la Guerre, la Philosophie, Correspondance. Paris: Robert Laffont, 1992. p. CCXVIII-CCXX.

O’MALLEY, J. W. Os primeiros jesuítas. São Leopoldo/Bauru: Unisinos/Edusc, 2004.

PASSOS, J. D.; SANCHEZ, W. L. (coord.). Dicionário do Concílio Vaticano II. São Paulo: Paulinas, $1^{\mathrm{a}}$. edição, 2015.

PEREIRA, M. A. Quintiliano Gramático: O papel do mestre de Gramática na Institutio Oratoria. São Paulo: Humanitas, 2000.

PRODI, P. Christianisme et monde moderne: Cinquante ans de recherches. Paris: Gallimard/Seuil, p. 85-99, 2006. (“'Réforme catholique et Contre-Réforme': le binôme de Jedin et l'historiographie italienne").

PROSPERI, A. "O missionário". In: VILLARI, R. O homem barroco. Lisboa: Presença, 1995. p. 145-71.

RENAUDET, A. Études érasmiennes (1521-1529). Paris: E. Droz, 1939. 
RODRIGUES, R. L.

RODRIGUES, R. L. Entre o dito e o maldito: Humanismo erasmiano, ortodoxia e heresia nos processos de confessionalização do Ocidente, 1530-1685. (Tese) Doutorado em teologia. São Paulo: FFLCH/USP, 2012.

RODRIGUES, R. L. "O fim da respublica christiana: as dinâmicas confessionais e a pré-história da noção de laicidade”. TQ 24 , p. 9-35, 2013.

RUMMEL, E. Erasmus' Annotations on the New Testament: From Philologist to Theologian. Toronto: University of Toronto Press, 1986.

RUMMEL, E. The Humanist-Scholastic Debate in the Renaissance and Reformation. Cambridge: Harvard University Press, 1998.

SNYDER, J. R. Dissimulation and the Culture of Secrecy in Early Modern Europe. Berkeley and Los Angeles: University of California Press, 2009.

TILLICH, P. História do Pensamento Cristão. 2 ed. São Paulo: ASTE, 2000.

TRACY, J. D. Erasmus of the Low Countries. Berkeley: University of California Press, 1996.

WILliAMS, G. H. La Reforma Radical. México: Fondo de Cultura Económica, 1983.

ZAGORIN, P. Ways of Lying. Dissimulation, Persecution, and Conformity in Early Modern Europe. Cambridge, MA: Harvard University Press, 1990.

Recebido: 08/12/2016

Received: 12/08/2016

Aprovado: 30/05/2017

Approved: 05/30/2017 